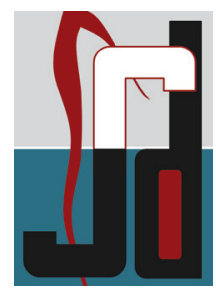

CASE SERIES

\title{
Excision Of Mucocele By Using Diode Laser: A Case Report
}

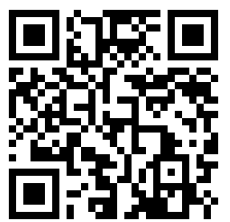

Navya.L.V ${ }^{1}$, Sabari.C ${ }^{2}$, Seema.G ${ }^{3}$

ABSTRACT : Background: Mucocele is the second most common benign soft tissue tumour occurring in the oral cavity. Clinically, a mucocele is characterized by an increase in volume, with a bubble-like shape that contains saliva, and is similarly colored to that of the normal mucosa or it may present blue coloration, depending on whether it is deep or superficial, respectively. A mucous cyst is common and harmless. However, if left untreated, it can organize and form a permanent bump on the inner surface of the lip. Literature contains a number of studies that confirm a traumatic etiology. This case report represents the treatment of a 22 year old male patient with a relapsing mucocele on the right side of the lower lip by diode laser as an alternative to conventional surgical technique due to its various advantages and also good patient acceptance.

Key Words: Mucocele, Diode Laser, Mucous extravasation cyst, Lower lip, Excision, Retention cyst.

\section{Introduction}

The term "Mucocele" (from Latin terms mucus, or mucus, and coele,or cavity) is used to define the accumulation of mucus secreted from salivary glands and their ducts in the oral cavity's subepithelial tissue. ${ }^{1}$ Clinically, a mucocele is characterized by an increase in volume, with a bubble-like shape that contains saliva, and is similarly colored to that of the normal mucosa or it may present blue coloration, depending on whether it is deep or superficial, respectively. ${ }^{2}$ By definition, they are not true cysts. The incidence is high, in the order of 2.5 lesions per 1000 individuals. Indeed, mucoceles are the most common minor salivary gland disorder, and represent the second most frequent benign soft tissue tumor of the oral cavity, following irritative fibromas. ${ }^{3}$

The principle etiology of a mucocele is mechanical trauma, causing the rupture of a salivary duct and consequent mucus extravasation within the surrounding tissue. ${ }^{4}$ A second mechanism for mucus accumulation is obstruction or narrowing of the salivary duct walls, causing ductal expansion. ${ }^{4}$ Mucoceles can be single or multiple often rupturing and leaving slightly painful erosions that usually heal within few days. ${ }^{5}$ The tentative diagnosis of a mucocele is made from the clinical history, clinical presentation and palpation, and the definitive diagnosis is made by histopathology. ${ }^{6}$
Treatment options for mucoceles include surgical excision, marsupialisation, micromarsupialization, cryosurgery, laser vaporization, and laser excision. ${ }^{7}$ Besides the conventional treatment options with the advent of high-intensity lasers, this type of lesion may be treated efficiently due to its prompt hemostasis and no need to suture, which reduces surgical time and reduces wound infection. ${ }^{8}$ In the present report mucocele was treated with diode laser and results are presented.

\section{Case Report}

A 22 year old male patient reported to the department of Periodontology, Sri Sankara Dental College, Varkala with a chief complaint of recurrent painless swelling over the lower lip since four months. Patient had given a history of swelling over lower lip since 4 months. Patient not given a history of lip biting. But given a history of trauma to the area due to accidently biting the area before 2 weeks. The swelling ruptured and there was bleeding. Again the swelling reappeared 1 week before with induration. Patient hadn't taken any treatment. No relevant medical history reported.

Intraoral examination showed a $0.5 \times 0.5 \mathrm{~cm}$ sized solitary and roughly round swelling present over the right lower labial mucosa in the region of 41 and 42. The color was the same as the adjacent mucosa (Figure 2). The surface appeard normal with no ulceration.The swelling was firm on palpation, nontender and sessile . 
Literature reviewed the clinical differential diagnosis, listing mucocele, fibroma, lipoma, , sialolith, phlebolith and salivary gland neoplasm as possibilities. Fibromas vary in consistency from soft to very firm. They are the most common intraoral soft-tissue lesion, and are seen most frequently on the lips (no distinction between upper and lower lips). Lipomas, neoplasms consisting of mature adipose tissue, are uncommon in the oral cavity, but can occur on the lips. Palpation can be helpful for a correct differential diagnosis. Lipomas and tumors of minor salivary glands present no fluctuation while cysts, mucoceles, abscess, and hemangiomas show fluctuation. ${ }^{9}$

The differential diagnosis of swelling of the lips in children should also include vascular malformations such as hemangiomas and varices. Usually blue in colour, these blanch under digital pressure, which distinguishes them from other pigmented lesions such as nevi, mucoceles, hematomas and melanomas. The appearance of mucoceles is pathognomonic and the following data are crucial: lesion location, history of trauma, rapid appearance, variations in size, bluish colour and the consistency. ${ }^{9}$

Based on history and clinical examination a provisional diagnosis of mucocele was made. Surgical removal of the lesion with a diode laser was planned and the specimen was send for histopathological examination.

\section{Surgical Management}

Local infiltrative anesthesia was applied (12 $\mathrm{mg}$ of $2 \%$ lidocaine with epinephrine 1:100,000). The anesthetic was not infiltrated directly into the lesion to avoid compromising the biopsy. The lip was then everted with digital pressure to increase the lesion's prominence. Removal of the lesion was performed using a diode laser at continuous mode in a contact technique with a power setting of $1 \mathrm{~W}$,wavelength $810 \mathrm{~nm}$. First a circular incision was made around the lesion to obtain a proper biopsy sample ( Figure:3). Dissection was performed, separating the lesion and associated minor salivary gland (Figure: 4). Once the lesion was excised the operative field was wiped with a sterile gauze soaked in $1 \%$ normal saline. Laser bandage was applied with 0.5 W power(Figure:6). Postoperative care included $0.2 \%$ chlorhexidine solution 3 times per day for one week and the patient was advised not to bite his lower lip to avoid recurrence of the lesion. The patient was also advised to avoid smoking, alcohol and spicy foods. The excised tissue was sent for biopsy(Figure:5). The patient was followed until complete healing was achieved, which occurred in 30 days (Figure:7). The patient was then reviewed every three months for a period of one ear and no recurrence was observed (Figure:8).

Histopathological examination showed multiple cystic spaces lined by granulation tissue. The lumen contained inflammatory exudate and mucin .Dense infiltrate of inflammatory cells were seen. A final diagnosis was confirmed as [retention cyst] (mucosa). (Figure 9, 10)

\section{Discussion}

The incidence of mucoceles in the general population is $0.4 \%$ to $0.8 \%$ with scant differences between males and females. As regards mucocele location in the oral cavity, most investigators consider the lower lip to be the most frequently affected location (40\% to $80 \%$ of all cases), followed by the cheek mucosa and floor of the mouth. ${ }^{2}$ Histologically two types of mucoceles are distinguished: retention mucocele and extravasation, greater majority were extravasation cyst. This case was retention mucocele. Patient not given a history of lip biting. There was no traumatic etiology. Retention mucocele are formed by dialation of the duct secondary to its obstruction or due to a sialolith or dense mucosa.

The primary objective in the treatment of mucocele is the complete resection of the lesion inorder to prevent its recurrence. We have to ensure that both the affected and neighbouring glands are removed along with the pathological tissue to avoid relapse. Several techniques have been proposed for the treatment of a mucocele, such as cryosurgery, micromarsupialization, marsupialisation, surgical excision and laser ablation.

The conventional method in the treatment is by surgical approach. But in conventional method there is more chance for rupturing the mucocele and leakage of its contents can cause soft tissue collapse with loss of anatomical references needed for resection. This will make the procedure more complicated and in addition special care is mandatory to avoid damage to other glands or ducts while suturing because this can even leads to its recurrence. Several cases of lower lip paresthesia after scalpel removal of a large mucocele is due to damage to terminal branch of mental nerve as 


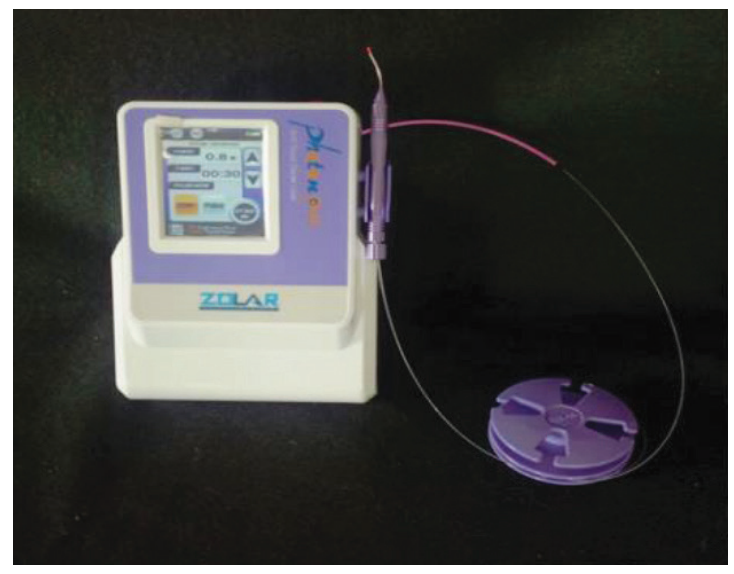

Figure1 Diode Laser

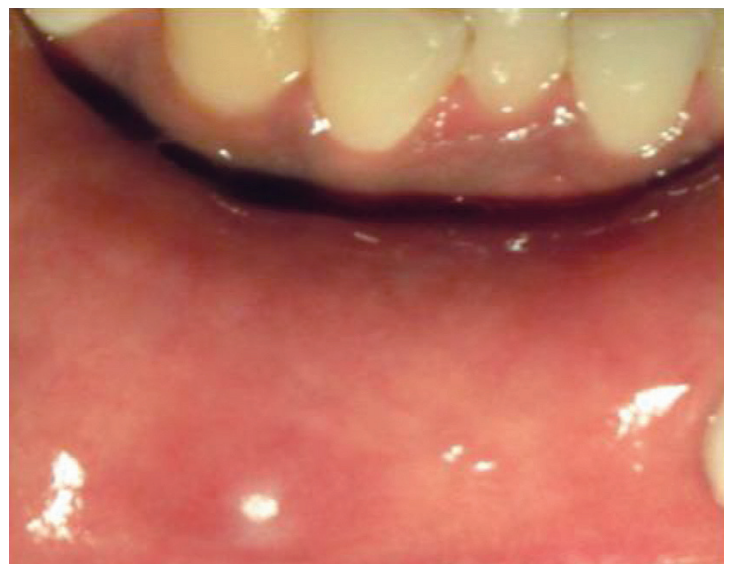

Figure 2 Initial view

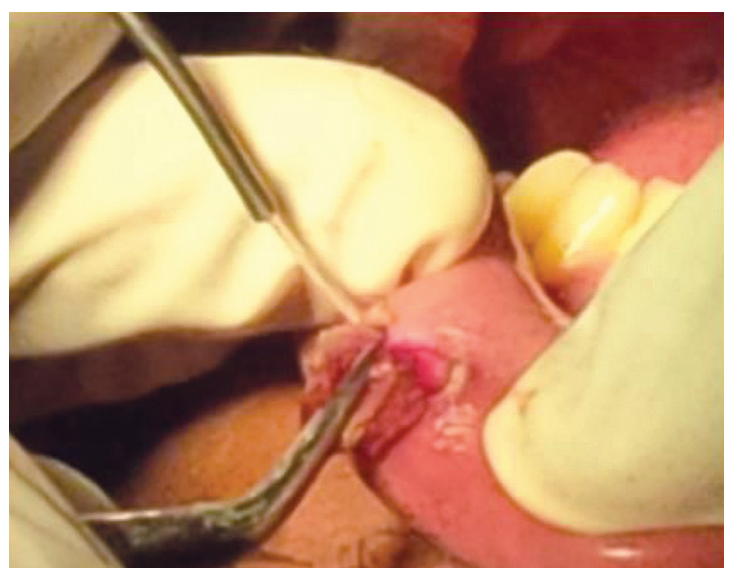

Figure 4 Laser excision

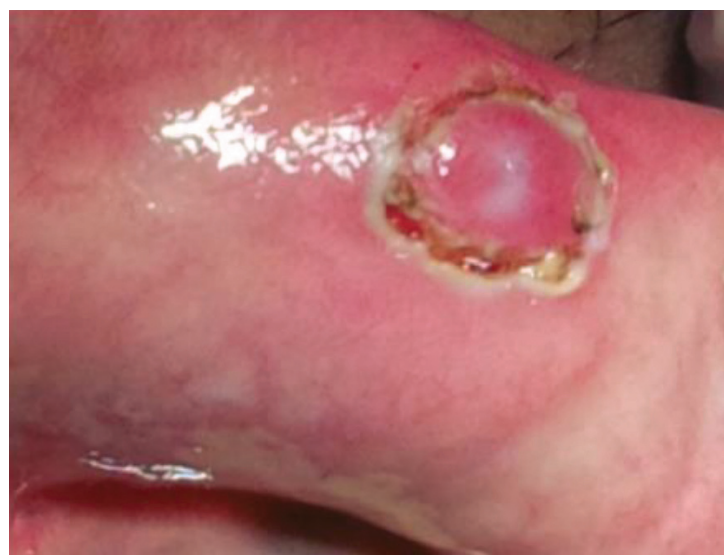

Figure 3 Circular incision around the lesion

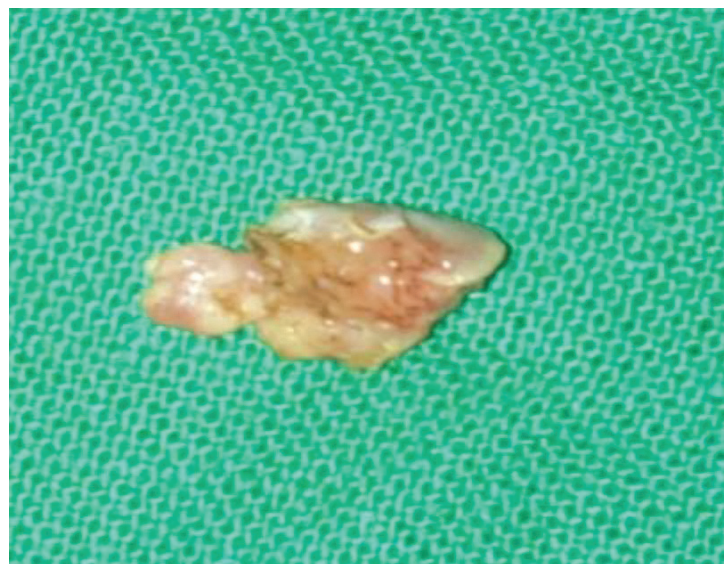

Figure 5 Excised tissue for Biopsy 


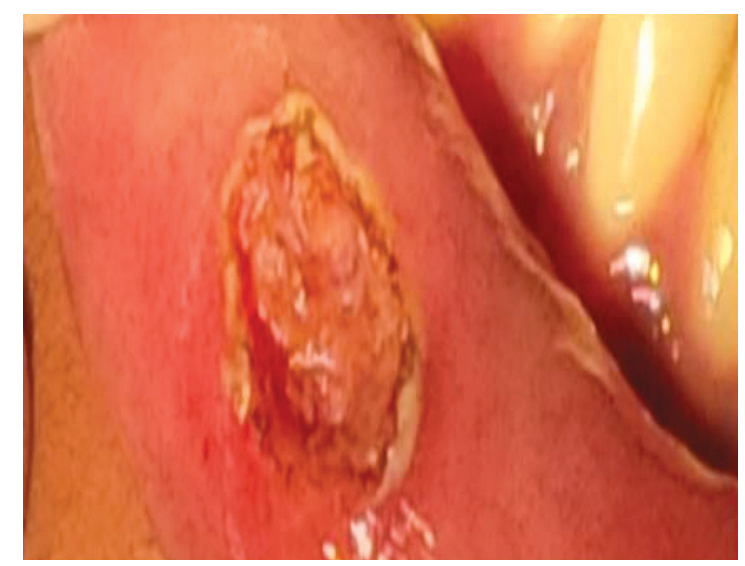

Figure 6 Immediate Post Operative View

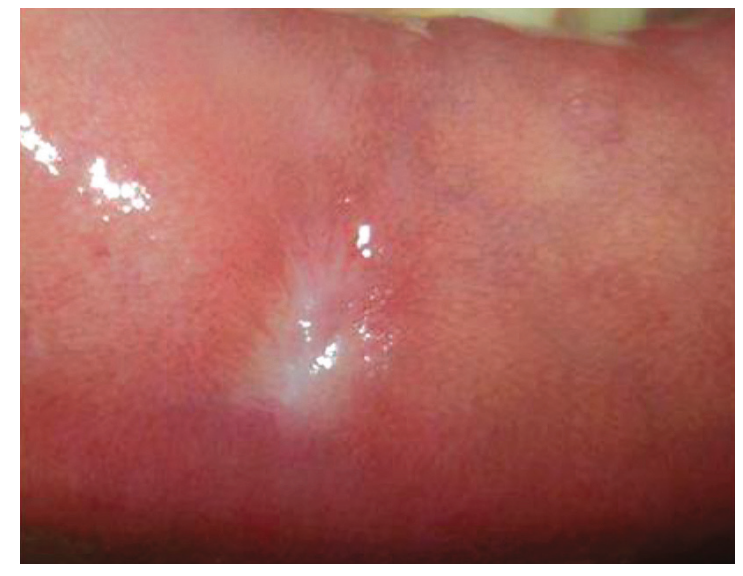

Figure 7 One Month Post Operative view

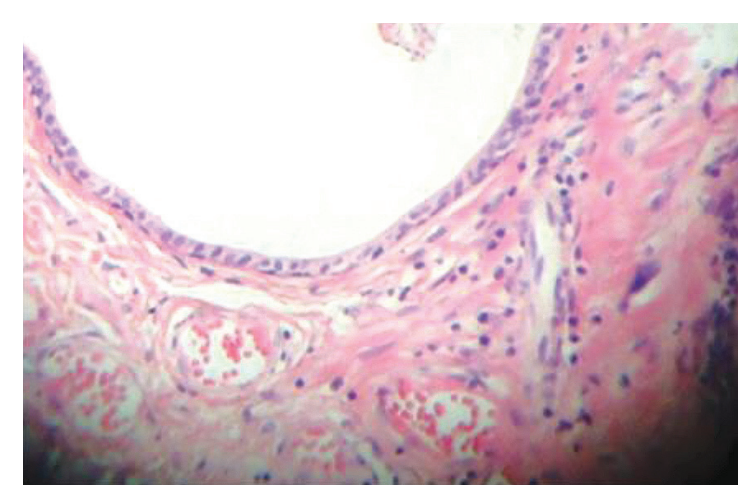

Figure 9 Histopathological slide (10X)

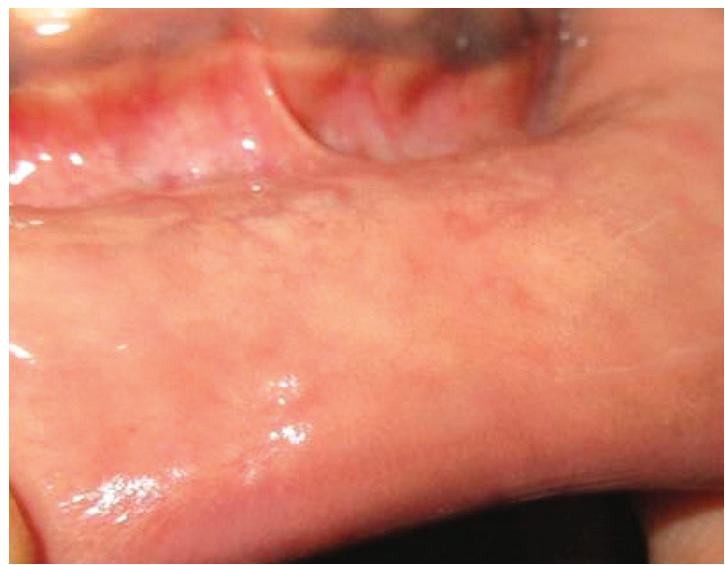

Figure 8 One Year Post Operative



Figure 10 Histopathological slide Stained with H\&E 4X Magnification 
a consequence of this complicated procedure is noted in literature. ${ }^{10}$

Marsupialization had resulted in considerably higher recurrence rates. Micromarsupialization had been suggested to have lower recurrence rates, although it was restricted to lesions with clinical characteristics that strongly suggested a diagnosis of mucocele, since histopathological examination was not possible. ${ }^{13}$

Cryosurgery yielded satisfactory results with no recurrence. Reported postoperative symptoms,

however, included marked edema and irritation, as well as a prolonged healing time. ${ }^{12}$

Vaporization with argon and Nd:YAG lasers has been described as a new technique for the treatment of mucoceles. Both lasers procedures presented satisfactory results with low recurrence rates and were well tolerated by the patients, whose discomfort was the main complaint reported. ${ }^{14}$

The diode laser has become an important tool in the dental armamentarium due to its exceptional ease of use and affordability. ${ }^{15}$ The diode laser (wavelength 800- $810 \mathrm{~nm}$ ), similarly to argon and Nd:YAG lasers, is intensely absorbed by hemoglobin, elevating the temperature and promoting coagulation and carbonization of soft tissues, such as the oral mucosa. The small size of the diode laser system, can be of great benefit as it will take up very little office space and assures great portability. ${ }^{11}$

The advantages in the removal of mucocele by diode laser are bloodless operating field, minimal discomfort, minimal scarring and much less or no postsurgical pain. The lesion is removed en mass so that it can be send for histopathological examination. Correct power setting should be carried out to avoid excessive thermal damage to soft tissues and to prevent unfavourable postoperative symptoms.

\section{Conclusion}

Diode lasers can be used for a variety of dental procedures which are predominantly soft tissue procedures and include soft tissue surgery. In comparison with conventional scalpel it has got various advantages like blood less operating field, ease of soft tissue ablation, instant sterilization, hemostasis, reduced bacteremia, little wound contraction, minimal swelling and scarring, reduced mechanical trauma, less discomfort and post operative pain with good patient acceptance.

\section{Acknowledgement}

I am grateful to Professor Dr. Seema G in guiding and discussing the case. I am also grateful to Dr. Sabari C ( Reader, department of periodontics) for his support during the clinical procedure. Also thankful to the patient and his family members for the utmost cooperation.

\section{Financial Support: Nil}

Conflicts Of Interest: No conflicts of interest

\section{References}

1. Sukhtankar LV et al, Treatment of Lower lip Mucocele with Diode Laser - A Novel Approach,Annals of Dental Research (2013) Vol 2 Suppl 1: 102-108.

2. Baurmash HD. Mucoceles and ranulas. J Oral Maxillofac Surg 2003;61:369-78

3. Baurmash H, The etiology of superficial oral mucoceles.J Oral Maxillofac Surg 2002;60:237-238.

4. J Ata-Ali1, C Carrillo2, C Bonet Oral mucocele: review of the literature J Clin Exp Dent. 2010;2(1):e18-21.

5. Anastassov GE, Haiavy J, Solodnik P, et al. Submandibular gland mucocele: diagnosis and management. Oral Surg Oral Med Oral Pathol Oral Radiol Endod 2000;89(2):159-

6. Tran TA,Parlette HL.Surgical pearl: Removal of a large labial mucocele. J Am Acad Dermatol 1999;40:760-762.

7. Huang IY, Chen CM, Kao YH,Worthington P. Treatment of mucocele of the lower lip with carbon dioxide laser. J Oral Maxillofac Surg 2007;65:855-8.

8. Irineu Gregnanin, Vivian. Treatment of Mucocele of the Lower Lip With Diode Laser in Pediatric Patients:Presentation of 2 Clinical Cases. Pediatric dentistry 2010;32:539-541.

9. Wood NK, Goaz PW. Lesions of the lips. In: Differential diagnosis of oral lesions. 5th ed. St. Louis (MO): Mosby Year Book; 2006. p. 561-79.

10. Jose Yague- Garcia, Antonio- Jesus- Espana, Leonardo Berini, Cosme Gay- Escoda. Treatment of oral mucocele - scalpel versus CO2 laser. Med Oral Patol Oral CirzzBucal.2009 Vep 
1; 14(9): e 469 - 74.

11. Samo pirnat. Versatality of an $810 \mathrm{~nm}$ Diode Laser in dentistry : An overview.

12. Neumann RA, Knobler RM. Treatment of oral mucous cysts with an argon laser.Arch Dermatol 1990;126:829-30.

13. Delbem AC, Cunha RF, Vieira AE, Ribeiro LL. Treatment of mucus retention phenomena in children by the micromarsupialization technique: Case reports. Pediatr Dent 2000;22:155-8.

\section{Address of Correspondence}

Dr. Navya .L.V

Post Graduate Student,

Department Of Periodontics,

Sri Sankara Dental College,

Akathumuri, Varkala, Trivandrum.
14. Jinbu Y, Tsukinoki K, Kusama M, Watanabe Y. Recurrent multiple superficial mucocele on the palate: Histopathology an laser vaporization. Oral Surg Oral Med Ora Pathol Oral Radiol Endod 2003;95:193-7.

15. Raffetto, Lasers for initial periodontal therapy, Dental Clin N Am 2004;48:923-936

\section{Authors:}

${ }^{1}$ Post Graduate Student,Department Of Periodontics, Sri Sankara Dental College, Akathumuri, Varkala, Trivandrum.

${ }^{2}$ Reader, Department Of Periodontics, Sri Sankara Dental College, Akathumuri, Varkala, Trivandrum.

${ }^{3}$ Professor, Department Of Periodontics, Sri Sankara Dental College, Akathumuri, Varkala, Trivandrum

\section{How to cite this article :}

Navya L.V, Sabari .C, Seema G. Excision Of Mucocele By Using Diode Laser: A Case Report. Journal of Scientific Dentistry, 2016;6(2):30-35

Source of Support : Nil, Conflicts of Interest : None declared 